\title{
A corner store intervention to improve access to fruits and vegetables in two Latino communities
}

\author{
Stephanie L Albert ${ }^{1}{ }^{*}$, Brent A Langellier ${ }^{2}$, Mienah Z Sharif ${ }^{1}$, Alec M Chan-Golston ${ }^{3}$, \\ Michael L Prelip ${ }^{1}$, Rosa Elena Garcia ${ }^{1}$, Deborah C Glik ${ }^{1}$, Thomas R Belin ${ }^{3}$, \\ Ron Brookmeyer ${ }^{3}$ and Alexander N Ortega ${ }^{2}$ \\ 'Department of Community Health Sciences, Fielding School of Public Health, University of California Los Angeles, \\ 650 Charles E. Young Drive South, 36-071 CHS, Los Angeles, CA 90095-1772, USA: ${ }^{2}$ Department of Health \\ Management and Policy, Dornsife School of Public Health, Drexel University, Philadelphia, PA, USA: ${ }^{3}$ Department of \\ Biostatistics, Fielding School of Public Health, University of California Los Angeles, Los Angeles, CA, USA
}

Submitted 17 October 2016: Final revision received 11 March 2017: Accepted 20 April 2017: First published online 5 June 2017

\begin{abstract}
Objective: Investments have been made to alter the food environment of neighbourhoods that have a disproportionate number of unhealthy food venues. Corner store conversions are one strategy to increase access to fruits and vegetables $(\mathrm{F} \& \mathrm{~V})$. Although the literature shows modest success, the effectiveness of these interventions remains equivocal. The present paper reports on the evaluation of Proyecto MercadoFRESCO, a corner store conversion intervention in two Latino communities.

Design: A repeated cross-sectional design was employed. Data were stratified by intervention arm and bivariate tests assessed changes over time. Logistic and multiple regression models with intervention arm, time and the interaction of intervention and time were conducted. Supplementary analyses account for clustering of patrons within stores and staggering of store conversions.

Setting: Three stores were converted and five stores served as comparisons in East Los Angeles and Boyle Heights, California, USA.

Subjects: Store patrons were interviewed before ( $n 550)$ and after $(n 407)$ the intervention.

Results: Relative to patrons of comparison stores, patrons of intervention stores demonstrated more favourable perceptions of corner stores and increased purchasing of $\mathrm{F} \& \mathrm{~V}$ during that store visit. Changes were not detected in store patronage, percentage of weekly dollars spent on food for $\mathrm{F} \& \mathrm{~V}$ or daily consumption of F\&V.

Conclusions: Consistent with some extant food environment literature, findings demonstrate limited effects. Investments should be made in multilevel, comprehensive interventions that target a variety retail food outlets rather than focusing on corner stores exclusively. Complementary policies limiting the availability, affordability and marketing of energy-dense, nutrient-poor foods should also be pursued.
\end{abstract}

Low-income and minority neighbourhoods frequently have higher density of convenience stores ${ }^{(1)}$ and fast-food establishments $^{(2,3)}$ and less access to supermarkets and grocery stores than majority-white and more affluent neighbourhoods ${ }^{(4-8)}$. Access to and availability of healthy foods (including fresh fruits and vegetables (F\&V)) and unhealthy foods (characterized as energy-dense foods high in sodium, salt and saturated fat) are associated with chronic health outcomes including obesity and diabetes ${ }^{(6,7)}$. In an effort to reduce well-documented disparities in weight-related health outcomes ${ }^{(9-12)}$, public health practitioners and researchers have developed, implemented and tested a range of interventions (e.g. introducing new comprehensive grocery stores, energy (calorie) labelling, limiting new fast-food establishments) aimed at improving the local food environment ${ }^{(13)}$.

A popular strategy for improving the availability of affordable healthy food options in 'food swamps', areas with excess unhealthy food options (i.e. an abundance of fast-food restaurants and limited comprehensive 
supermarkets) ${ }^{(14,15)}$, is the corner store conversion. Such efforts work with existing small corner stores that carry minimal fresh produce or other healthy foods and instead sell primarily alcohol, tobacco, soda, candy and snack foods, such as potato chips ${ }^{(16)}$. In a prototypical corner store conversion, stores are able to stock additional healthy food items such as fresh produce and make aesthetic improvements (e.g. rearranging merchandise) to make healthy items more visible within the store ${ }^{(17)}$.

There are several benefits to working with existing corner stores. First, the time and financial costs associated with opening a new store are avoided ${ }^{(18)}$. Second, investing directly in local businesses and transforming them into healthy community assets may result in greater opportunities for community buy-in and long-term sustainability ${ }^{(17,18)}$. And, as with public health efforts more generally, partnering with stores that have a long history of interacting with and understanding the food purchasing behaviours of community residents can also help to tailor corner store conversions to the tastes and preferences of store patrons ${ }^{(17,18)}$.

There is an emerging body of research examining the effectiveness of corner store conversions for increasing the availability and purchasing of healthy foods, improving dietary practices, as well as reducing chronic disease burden in low-income and minority communities. A pair of systematic reviews has descriptively documented the value of this strategy. In 2012, Gittelsohn et al. reviewed sixteen small store studies in the USA and abroad, and determined that corner store conversions were mostly associated with improved availability of healthy foods and sales, purchasing and consumption of promoted items ${ }^{(19)}$. A more recent review by Pinard et al. in 2016 highlighted five intervention studies in urban food environments that similarly documented positive outcomes ${ }^{(20)}$. Although reviews of the interventions have suggested conversions to be an effective strategy, individual studies have had mixed findings, highlighting the heterogeneity in outcomes and approaches involved. For example, an intervention in North Carolina that aimed to promote sales of $\mathrm{F} \& \mathrm{~V}$ in small stores found increased availability of fresh and canned vegetables without corresponding improvements in availability of fruits ${ }^{(21)}$. That study also found a marginally significant increase in consumption of F\&V yet an unexpected decline in self-efficacy for consumption of additional F\&V. Similarly, a large-scale intervention to increase the availability of healthier products in Philadelphia corner stores found no significant improvements in the nutritional content of purchases made in corner stores $^{(22)}$. An intervention to improve the visibility and quality of $\mathrm{F} \& \mathrm{~V}$ in corner stores in a low-income urban area of Massachusetts found that sales of these items increased among participants of the Special Supplemental Nutrition Program for Women, Infants, and Children who shopped in intervention stores but not in control stores, yet increases in self-reported purchases of these items over time did not reach statistical significance ${ }^{(23)}$. Methodological limitations of existing research such as short study time frames, small sample sizes, lack of comparison or control groups, and imprecise measures may have contributed to mixed findings ${ }^{(13,17)}$.

In a recent study, we used community surveys to evaluate the impact of Proyecto MercadoFRESCO, an intervention that converted corner stores and conducted a community-wide social marketing campaign on healthy eating in Boyle Heights and East Los Angeles, California, USA. That study utilized pre- and post-intervention household surveys in the neighbourhoods surrounding three intervention and five comparison stores to determine community residents' perceptions of the food environment and corner stores, patronage of corner stores, food purchasing patterns and F\&V consumption ${ }^{(24,25)}$. Households were selected based on their proximity to the intervention and comparison stores and residents were interviewed regardless of whether the occupants shopped at the study stores. The aim of that study was to determine whether community-level changes could be achieved by improving the food environment through corner store conversions and narrowcast social marketing. Perceptions regarding food accessibility and corner stores improved over time among residents in both intervention and comparison communities, calling into question whether self-reported differences could be attributable to the intervention or instead were driven by contextual factors. The community surveys also did not yield evidence of significant improvement in store patronage, purchasing of $\mathrm{F} \& \mathrm{~V}$ or consumption of $\mathrm{F} \& \mathrm{~V}$. The mixed findings were consistent with results from other studies ${ }^{(19,21,22)}$. The community survey approach was innovative in that, to our knowledge, no previous corner store conversion study had measured community-level effects, but as was understood at the study design stage, such an approach leaves open the possibility that a corner store conversion could have meaningful effects on store patrons that might not be manifested in downstream effects in the community.

The current study builds on our previously reported community-level findings ascertained by household surveys by assessing the impact of the Proyecto MercadoFRESCO intervention specifically among patrons of intervention and comparison stores using a separate patron survey. In particular, we examine perceptions about corner stores, store patronage, food purchasing patterns and $\mathrm{F} \& \mathrm{~V}$ consumption pre- $v$. post-intervention. Patrons of converted stores are a key group to evaluate because it can reasonably be expected that the effects on perceptions and behaviours would be largest among these individuals. Furthermore, the effectiveness of corner store conversions has almost exclusively been evaluated with respect to patron outcomes, rather than community outcomes; therefore the findings we report here can be directly compared with prior studies. Given the expanded focus in public health research on food environment 
interventions, as well as expanded public and private funding for corner store conversions ${ }^{(26)}$, it is important to understand the extent to which this type of intervention is associated with measurable improvements in public health outcomes.

\section{Methods}

\section{Community context}

A detailed description of Proyecto MercadoFRESCO can be found elsewhere ${ }^{(24,25)}$. The study was implemented in the neighbouring communities of East Los Angeles and Boyle Heights, California, USA. These neighbouring communities in Los Angeles County are majority Latino $(97 \cdot 1 \text { and } 95.4 \% \text {, respectively })^{(27,28)}$ and have high rates of adult obesity $(29 \cdot 7 \text { and } 35.0 \% \text {, respectively })^{(29,30)}$. Furthermore, both communities can be considered food swamps because they have a high density of fast-food and convenience stores in relation to healthier retailers such grocery or produce stores and farmers' markets ${ }^{(31-33)}$. Thus, these neighbourhoods were identified as areas where public health outcomes might benefit from intervention with food retailers.

\section{Study design}

With the help of a consultant to Proyecto MercadoFRESCO who had relevant experience converting corner stores, eight stores were identified as candidates for participation. Four stores were recruited to receive active intervention of a corner store conversion. Comparison stores were then identified that matched the intervention stores on salient characteristics. To limit the possibility of spillover effects (i.e. experimental contamination), comparison stores were located at least $1.6 \mathrm{~km}$ ( 1 mile) away and were separated by a major freeway from the intervention stores. The original project budget included \$US 25000 for each store conversion, excluding any expenses related to social marketing campaigns. Given constraints on project staff and community partner resources, store conversions were initiated one at a time at staggered time intervals. Stores were converted in autumn 2011, winter 2012 and winter 2013.

One proprietor at an active intervention site lost interest in participating soon after store conversion efforts were supposed to begin. In addition to serving as a cautionary example for practitioners planning store conversions, the anticipated impact on intent-to-treat analyses led to a decision to group results from that site with findings from the comparison stores in the analyses presented here.

\section{Intervention}

The intervention was informed by the social ecological theory. The theory suggests that there are multiple levels of influence on human behaviour and that health promotion interventions must not only change individuals but also change the social and physical environment in order to be successful ${ }^{(34)}$. From mid-2011 to the end of 2015, we implemented a multicomponent food environment intervention. The first component was the conversion of neighbourhood corner stores to be healthy food outlets. This component operated at the community level of the social ecological theory. Storeowners worked with project staff, community partners and local high school youth to renovate both the interior and exterior of their locations. Upgrades included making general repairs, installing new windows and adding security systems to improve the stores. The exterior of each store was painted a vibrant colour selected by the storeowner. The store interiors were modified with paint, installation of new refrigeration units to display newly available fresh $F \& V$, and replacement of alcohol and tobacco marketing materials with social marketing materials encouraging the consumption of F\&V. Additionally, store merchandise was reorganized so that healthy items, including newly available produce, were displayed near the entrance of the stores while unhealthy items, such as chips and soda, were moved to the back of the stores. Each store conversion took approximately 1 month to complete but was done on a staggered basis. Both intervention and comparison stores were regularly monitored for fidelity. In intervention stores, the study team monitored the availability and quality of fresh produce as well maintenance of social marketing materials promoting F\&V consumption, while in comparison stores the team assessed whether any comparable improvements were made to stores or their merchandise. Storeowners also received training and technical assistance in purchasing and handling of merchandise as well as in improving business practices.

The second component of the intervention was community-wide social marketing and interactive educational campaigns led by local youth ${ }^{(35)}$, which were implemented to create awareness that healthy foods were being made available in these stores, to increase store patronage among neighbourhood residents, to increase purchasing of newly available items at the corner stores and to increase consumption of F\&V. These campaigns targeted residents who lived near and around converted corner stores. Social marketing and educational efforts began immediately prior to the grand reopening of each store and continued for the remainder of the intervention period. Thus, the social marketing and educational activities were longest for the first converted store and shortest for the last converted store. This component of the intervention operated at both the individual and interpersonal levels of the social ecological theory.

\section{Sample}

The present study employed a repeated cross-sectional design in which surveys were administered before and after the intervention. Data were collected from an intercept survey of patrons of study corner stores. These were surveys among persons exiting the stores and conducted 
in the immediate vicinity of the store. Prior to store conversion efforts, approximately eighty in-person intercept interviews were conducted at each of the intervention and comparison stores. Patron surveys were conducted at various times of the day (i.e. morning, afternoon, evening) and days of the week (i.e. weekdays and weekends). Patrons who resided within four blocks of the stores, had purchased food or beverages from the stores during that visit, and were at least 18 years old were eligible to participate. The interviews, conducted in either English or Spanish, took approximately $10 \mathrm{~min}$ to complete and respondents were given \$US 5 vouchers to the stores as an incentive. Participating stores were reimbursed for each redeemed voucher.

Baseline data were collected between August 2011 and December 2012. Six hundred and forty-two pre-intervention interviews were completed, corresponding to a response rate of $65 \%$ using the AAPOR- 4 standard of the American Association for Public Opinion Research (AAPOR). The AAPOR-4 standard incorporates an estimate of the proportion of people who would be eligible among those with unknown eligibility, which was necessary because eligibility could not be determined for all patrons due to there being a limited number of interviewers. Given the staggered timelines of corner store conversions, the follow-up data were collected between August 2012 and December 2015. During this wave of data collection, intercept interviews were fielded at the three intervention stores and only three comparison stores, for a total of 482 completed interviews and an AAPOR- 4 response rate of $65 \%$. The cooperation rate at both baseline and follow-up exceeded $90 \%$ when calculated only using the number of completed surveys divided by the number of individuals for whom eligibility was determined.

\section{Measures}

Four outcome domains were used to assess the effectiveness of the intervention among patrons. First, perceptions of corner stores were measured using fifteen individual items representing major themes about corner stores identified during the formative stage of the study. Questions were developed by the research team and were pre-tested with twenty community residents to improve clarity and determine relevancy. Questions included items such as 'corner stores sell a wide variety of fresh fruits' and 'the fresh vegetables sold at corner stores are of good quality'. Respondents were asked to indicate whether each statement was true. Responses indicating a positive perception of a corner store were coded as 1, while responses indicating a negative perception or 'don't know' were coded as 0 . These indicators were summed to produce a total score with a possible range of 0 to 15 . Cronbach's $\alpha$ for this measure was $0 \cdot 80$, indicating good internal consistency among the items.

The second outcome domain was patronage of the store. Patronage was measured with one question,
'How often do you shop for food at this corner store?', with five response options: 'more than once a day', 'once a day', 'a few times a week', 'a few times a month' and 'every once in a while'. This measure was collapsed into frequent patronage (i.e. 'a few times a week' or more) $v$. infrequent patronage (i.e. 'a few times a month' or 'every once in a while').

The third outcome domain, food purchasing, was assessed by asking participants to report the total number of dollars spent on food per week and, of that amount, how much was used to purchase canned, frozen or fresh $F \& V$. The percentage of the total that was spent on F\&V was then calculated by dividing the reported amount spent on produce by the reported total spent on all food per week. Additionally, F\&V purchases during that store visit were measured with two questions, one asking what vegetables were purchased and the other asking what fruits were purchased during the visit. For each of these questions, the number of different varieties of fresh, frozen or canned fruits or vegetables purchased during the visit was recorded. The number of varieties of fruits and number of varieties of vegetables purchased were then summed to represent total F\&V purchases.

Finally, F\&V consumption was measured using two questions adapted from the Townsend Food Behavior Checklist ${ }^{(36)}$. Participants were asked how many servings of fruit they eat on a typical day and how many servings of vegetables they eat on a typical day. No additional instructions or clarifications were given to participants regarding serving sizes. The sum was used to reflect total daily F\&V intake. To address the possibility of outlying values, a reported number of servings greater than 20 was coded as 20 .

Available demographic measures included sex, age (in years), marital status (single, married/with partner, separated/divorced/widowed), nativity status (US-born $v$. foreign-born), Mexican heritage (yes $v$. no), language of interview (English $v$. Spanish) and highest level of education (less than high school, high school/General Educational Development, associate degree, bachelor's degree, graduate degree).

\section{Statistical analyses}

The statistical software package Stata version 14.0 was used to perform all statistical analyses. Results are presented in three parts. Descriptive summaries are presented for the sample of participants by intervention arm (intervention or comparison) and by time point (baseline or follow-up). Patron perceptions of corner stores are shown before and after corner store conversions. Data were stratified by intervention arm and $\chi^{2}$ tests were performed for the fifteen dichotomous perception variables by time point. Additionally, logistic regression models were used to assess the interaction between intervention arm and time. Overall perceptions of corner stores, store patronage and $F \& V$ purchasing and consumption are displayed for both intervention arms by time. Data were again stratified by intervention arm, and within each intervention arm 
independent-sample $t$ tests were used to test for significant differences in the continuous summary perception score and the purchasing and consumption variables. The mean difference (follow-up - baseline) between intervention and comparison samples was tested using an $F$ test on the interaction term of a linear regression. Significant differences in the dichotomous patronage variable by condition were evaluated with the same methods used on the dichotomous perception variables. Supplementary analyses repeated the aforementioned regressions but included store indicator variables to control for store effects and clustering. The results of these regression models are not shown, as they agreed with all tests of significance and saw only minor changes in regression coefficients and standard errors. Lastly, in order to account for potential differences in responses due to time of exposure to the converted corner stores, the number of days from the reopening of the corner store to the day of the follow-up interview was calculated for each individual in the intervention group. A three-way interaction between this time variable, treatment status and the indicator of follow-up was included in all regression models. The inclusion of this interaction term allows the treatment effect to vary by the duration of time that the intervention (i.e. corner store conversion and social marketing) was in place.

At each time point only those individuals with data for all variables of interest were analysed (baseline $n$ 550; follow-up $n$ 407). Comparability in demographic characteristics as well as the outcome measures between the full sample and the analytic sample was assessed. The only statistically significant differences between the two samples were in language of interview and age. Specifically, a larger percentage of the analytic sample elected to have the survey administered in Spanish and they were slightly older ( 2.6 years) as compared with the full sample. However, no differences were detected in overall perceptions about corner stores, shopping at corner stores at least a few times per week, percentage of food dollars spent on F\&V, number of F\&V purchased at the store during this visit and servings of F\&V consumed each day. Despite minor differences, the analytic sample seems to be representative of the larger sample. $P$ values less than 0.05 were considered statistically significant.

\section{Results}

\section{Descriptive characteristics}

At baseline and at follow-up, a majority of participants were female, were 44 years old or younger, were married or with a partner, were foreign-born, were of Mexican heritage, had a high school education or less, and shopped at the corner store at least a few days per week (see Table 1). At baseline, a smaller percentage of participants from intervention stores indicated they were of Mexican heritage as compared with those from comparison stores. Similarly, there were differences in educational attainment across the intervention arms. At follow-up, the intervention and comparison groups differed in terms of education and frequency of shopping at the corner store.

\section{Perceptions of corner stores}

When stratified by intervention arm, there were statistically significant improvements over time for ten of the fifteen items measuring perceptions about corner stores among the intervention sample as compared with five of the fifteen items among the comparison sample (see Table 2). Specifically, after the corner store conversion, more participants in the intervention arm reported greater availability of a variety of fresh fruits $(88.5 \mathrm{v} .48 .5 \%$; $P<0.001)$, fresh vegetables $(91.8 v .45 .1 \% ; P<0.001)$, frozen or canned fruits $(68.3 v .59 .1 \% ; P<0.05)$ and frozen or canned vegetables $(66.3 v .55 .3 \% ; P<0.05)$ at the corner store. There was also an increase in the perceived quality of fruits $(88.9 v .67 .0 \% ; P<0.001)$ and vegetables (96.2 v. 62.1\%; $P<0.001)$ available for sale at the store. Compared with baseline, more participants at follow-up indicated that healthy foods were available $(94.7 v .75 \cdot 8 \%$; $P<0.001)$ and that they could get information about healthy eating $(76.0 v .49 .6 \% ; P<0.001)$ at the corner store. Finally, there were improved perceptions regarding the cleanliness of the store $(96.2 v .88 .3 \% ; P<0.01)$ and perception that the store was not dangerous (98.1 $v$. $94.3 \% ; P<0.05)$ following the store conversion.

Among the comparison sample there were significant improvements over time in terms of the availability of a variety of fresh vegetables $(56.3$ v. $45.1 \% ; P<0.05)$, quality of fresh fruits $(75.4 v \cdot 62.2 \% ; P<0.01)$, quality of fresh vegetables $(66.3 v .56 .3 \% ; P<0.05)$, perceived quality of customer service $(98.5 v .89 .2 \% ; P<0.001)$ and language concordance between staff and customers (94.0 v. $86.7 \% ; P<0.05)$ at the corner store.

When testing for an interaction between intervention arm and time, results showed an overall pattern in favour of intervention stores with one exception. The changes in perceptions were greater in intervention stores than comparison stores for the following characteristics: availability of a variety of fresh fruits, availability of a variety of fresh vegetables, quality of fresh fruit, quality of fresh vegetables, availability of healthy foods and ability to get information on healthy eating at the store. The one exception was in terms of customer service, where comparison stores improved more relative to intervention stores; however, at baseline $97.3 \%$ of store patrons at intervention stores indicated that the stores had good customer service, suggesting a ceiling effect.

The fifteen individual items were summed to represent the number of positive perceptions of corner stores. Table 3 shows that over time overall positive perceptions of corner stores improved for both samples. Furthermore, the test of an intervention effect confirmed that patrons' perceptions of intervention stores improved more relative to patrons' perceptions of comparison stores. 
Table 1 Characteristics of the Proyecto MercadoFRESCO patron sample ( $n$ 957), East Los Angeles and Boyle Heights, California, USA, mid-2011 to 2015

\begin{tabular}{|c|c|c|c|c|}
\hline \multirow[b]{2}{*}{ Characteristic } & \multicolumn{2}{|c|}{ Baseline percentage } & \multicolumn{2}{|c|}{ Follow-up percentage } \\
\hline & $\begin{array}{l}\text { Intervention } \\
\text { (n 264) }\end{array}$ & $\begin{array}{l}\text { Comparison } \\
\quad(n \text { 286) }\end{array}$ & $\begin{array}{l}\text { Intervention } \\
\quad(n \text { 208) }\end{array}$ & $\begin{array}{c}\text { Comparison } \\
(n \text { 199) }\end{array}$ \\
\hline \multicolumn{5}{|l|}{ Sex } \\
\hline Male & $46 \cdot 2$ & $42 \cdot 0$ & 34.6 & $38 \cdot 7$ \\
\hline Female & $53 \cdot 8$ & $58 \cdot 0$ & 65.4 & $61 \cdot 3$ \\
\hline \multicolumn{5}{|l|}{ Age (years) } \\
\hline $18-30$ & $36 \cdot 4$ & $36 \cdot 0$ & $29 \cdot 8$ & $33 \cdot 7$ \\
\hline $31-44$ & $29 \cdot 6$ & $31 \cdot 8$ & 21.3 & 34.7 \\
\hline $45-64$ & 28.0 & $27 \cdot 3$ & 32.2 & 29.2 \\
\hline $65+$ & $6 \cdot 1$ & 4.9 & $6 \cdot 7$ & 2.5 \\
\hline \multicolumn{5}{|l|}{ Marital status $†$} \\
\hline Single & $37 \cdot 8$ & $31 \cdot 8$ & 28.9 & 29.4 \\
\hline Married/with partner & $44 \cdot 3$ & 51.4 & 49.5 & $53 \cdot 6$ \\
\hline Separated/divorced/widowed & 17.9 & $16 \cdot 8$ & 21.6 & $17 \cdot 0$ \\
\hline \multicolumn{5}{|l|}{ Nativity } \\
\hline US-born & 40.5 & $35 \cdot 7$ & $35 \cdot 6$ & 44.2 \\
\hline Foreign-born & 59.5 & $64 \cdot 3$ & 64.4 & $55 \cdot \overline{8}$ \\
\hline \multicolumn{5}{|l|}{ Mexican heritageł } \\
\hline Yes & 85.9 & $91.6^{*}$ & 93.6 & $92 \cdot 8$ \\
\hline No & $14 \cdot 1$ & 8.4 & 6.4 & $7 \cdot 2$ \\
\hline \multicolumn{5}{|l|}{ Language of interview } \\
\hline English & $46 \cdot 6$ & $42 \cdot 3$ & 43.8 & $48 \cdot 7$ \\
\hline Spanish & 53.4 & $57 \cdot 7$ & $56 \cdot 3$ & 51.3 \\
\hline \multicolumn{5}{|l|}{ Education } \\
\hline Less than high school & $45 \cdot 8$ & $47 \cdot 9^{\star}$ & 48.6 & $32 \cdot 3^{*}$ \\
\hline High school graduate or GED & 37.5 & 43.4 & 41.3 & $56 \cdot 3$ \\
\hline Associate degree & $13 \cdot 3$ & $6 \cdot 3$ & $6 \cdot 7$ & $5 \cdot 0$ \\
\hline Bachelor's degree & 1.9 & 2.5 & 2.9 & 5.5 \\
\hline Graduate degree & 1.5 & 0.0 & 0.5 & 0.5 \\
\hline \multicolumn{5}{|c|}{ How often do you shop at this store? } \\
\hline More than once per day & $24 \cdot 6$ & $32 \cdot 9$ & 27.9 & $39 \cdot 2^{*}$ \\
\hline Once per day & $25 \cdot 0$ & $20 \cdot 9$ & $22 \cdot 1$ & 24.6 \\
\hline A few times a week & $34 \cdot 1$ & 32.5 & 38.5 & $30 \cdot 7$ \\
\hline A few times a month & 4.6 & 3.9 & 4.3 & $2 \cdot 0$ \\
\hline Every once in a while & 11.7 & 9.8 & 7.2 & 3.5 \\
\hline
\end{tabular}

GED, General Educational Development.

Significant differences in categorical variables were tested between intervention and comparison using $x^{2}$ tests at both baseline and follow-up. Percentages may sum to greater than 100 due to rounding.

${ }^{\star} P<0.05$.

†Data were available only for $262(99.2 \%)$ of the baseline intervention group and $194(97.5 \%)$ of the follow-up comparison group due to missing data.

łData were available only for $256(97.0 \%)$ of the baseline intervention group, $204(98.1 \%)$ of the follow-up intervention group and 194 $(97.5 \%)$ of the follow-up comparison group due to missing data.

\section{Patronage}

Among the intervention sample, the frequency of shopping at corner stores remained relatively consistent before and after the intervention. At both time points, the vast majority of participants reported being frequent shoppers (i.e. a few times a week or more) at an intervention store. Conversely, among the comparison store sample, the percentage of respondents who indicated they were frequent patrons of corner stores increased from 86.4 to $94.5 \%(P<0 \cdot 01)$. Additional tests found no evidence of an intervention effect, suggesting that there was not differential change over time for the two samples (see Table 3).

\section{Purchasing}

There were no appreciable differences observed over time for either the intervention or comparison sample in the percentage of dollars spent on F\&V per week. At both time points both groups reported spending roughly a third of their weekly food budget on $\mathrm{F} \& \mathrm{~V}$. A test of an intervention effect was also non-significant (see Table 3).

Among the intervention store sample, the average number of $F \& V$ purchased during the most recent trip to the store increased from 0.2 to $0.5(P<0.001)$ from baseline to follow-up. No corresponding statistically significant differences were observed over time among patrons from comparison stores. Further analyses found that there was a significant interaction of time and treatment, suggesting the improvements seen in the intervention store sample were significantly greater than those in the comparison store sample $(P<0 \cdot 001$; see Table 3$)$.

\section{Fruit and vegetable consumption}

The number of servings of F\&V consumed each day showed no significant change between baseline and 
Table 2 Perceptions about corner stores and patronage by intervention status and time among the Proyecto MercadoFRESCO patron sample ( $n$ 957), East Los Angeles and Boyle Heights, California, USA, mid-2011 to 2015

\begin{tabular}{|c|c|c|c|c|c|c|}
\hline \multirow[b]{2}{*}{ Corner store characteristic } & \multicolumn{2}{|c|}{$\begin{array}{l}\text { Intervention } \\
\text { percentage }\end{array}$} & \multicolumn{2}{|c|}{$\begin{array}{l}\text { Comparison } \\
\text { percentage }\end{array}$} & \multicolumn{2}{|c|}{$\begin{array}{l}\text { Percentage difference } \\
\text { (follow-up - baseline) }\end{array}$} \\
\hline & $\begin{array}{l}\text { Baseline } \\
\text { (n 264) }\end{array}$ & $\begin{array}{l}\text { Follow-up } \\
\text { (n 208) }\end{array}$ & $\begin{array}{l}\text { Baseline } \\
(n 286)\end{array}$ & $\begin{array}{l}\text { Follow-up } \\
(n \text { 199) }\end{array}$ & Intervention & Comparison \\
\hline This store sells a wide variety of fresh fruits & 48.5 & $88 \cdot 5^{\star \star \star}$ & 41.6 & 49.7 & $40 \cdot 0$ & $8 \cdot 1^{\star \star \star}$ \\
\hline This store sells a wide variety of fresh vegetables & $45 \cdot 1$ & $91 \cdot 8^{\star \star \star}$ & $45 \cdot 1$ & $56 \cdot 3^{*}$ & $46 \cdot 8$ & $11 \cdot 1^{\star \star \star}$ \\
\hline This store sells a wide variety of frozen or canned fruits & $59 \cdot 1$ & $68 \cdot 3^{*}$ & $57 \cdot 0$ & $60 \cdot 1$ & $9 \cdot 2$ & 3.8 \\
\hline This store sells a wide variety of frozen or canned vegetables & $55 \cdot 3$ & $66 \cdot 3^{*}$ & $51 \cdot 0$ & 57.8 & $11 \cdot 0$ & 6.7 \\
\hline The fresh fruits sold at this store are not of poor quality $\dagger$ & $67 \cdot 0$ & $88 \cdot 9^{\star * \star}$ & $62 \cdot 2$ & $75 \cdot 4^{\star *}$ & 21.9 & $13 \cdot 1^{*}$ \\
\hline The fresh vegetables sold at this store are of good quality & $62 \cdot 1$ & $96 \cdot 2^{\star \star *}$ & $56 \cdot 3$ & $66 \cdot 3^{*}$ & $34 \cdot 0$ & $10 \cdot 0^{* * *}$ \\
\hline This store sells healthy food & $75 \cdot 8$ & $94 \cdot 7^{\star * *}$ & $75 \cdot 9$ & 81.4 & $19 \cdot 0$ & $5 \cdot 5^{\star \star}$ \\
\hline I can get information about nutrition and healthy eating at this store & $49 \cdot 6$ & $76 \cdot 0^{\star \star \star}$ & $46 \cdot 2$ & $44 \cdot 7$ & $26 \cdot 3$ & $-1 \cdot 4^{\star \star \star}$ \\
\hline This store is not dirty $\ddagger$ & $88 \cdot 3$ & $96 \cdot 2^{\star \star}$ & $90 \cdot 9$ & $94 \cdot 0$ & 7.9 & $3 \cdot 1$ \\
\hline This store is not dangerous $\S$ & $94 \cdot 3$ & $98 \cdot 1^{*}$ & 94.4 & $97 \cdot 0$ & $3 \cdot 8$ & $2 \cdot 6$ \\
\hline This store has good customer service & $97 \cdot 3$ & 97.6 & 89.2 & $98 \cdot 5^{\star \star \star}$ & 0.2 & $9 \cdot 3^{*}$ \\
\hline This store sells traditional Latino food ingredients & $85 \cdot 2$ & 89.9 & $87 \cdot 8$ & $90 \cdot 0$ & 4.7 & $2 \cdot 2$ \\
\hline The staff at this store speaks my language & 93.2 & $92 \cdot 8$ & $86 \cdot 7$ & $94.0^{*}$ & -0.4 & $7 \cdot 3$ \\
\hline The food sold at this store is not expensive $\|$ & 67.4 & $69 \cdot 2$ & $55 \cdot 9$ & $57 \cdot 3$ & 1.8 & 1.3 \\
\hline It is convenient to shop at this store & 87.9 & $92 \cdot 8$ & $85 \cdot 3$ & $87 \cdot 4$ & 4.9 & $2 \cdot 1$ \\
\hline
\end{tabular}

Significant differences in binary variables were tested between intervention baseline and follow-up using $x^{2}$ tests, comparison baseline and follow-up using $x^{2}$ tests, and percentage difference (follow-up - baseline) for intervention and comparison using a Wald test on the interaction term of a logistic regression. This Wald test can be thought of as testing whether the relative change (on an odds ratio scale) is the same in the intervention and comparison groups. Percentage difference may vary slightly from reported percentage follow-up - reported percentage baseline due to rounding. ${ }^{\star} P<0.05,{ }^{* \star} P<0.01,{ }^{* \star *} P<0.001$.

†Question was reverse coded. Original statement was 'The fresh fruits sold at this store are of poor quality'.

$\ddagger$ Question was reverse coded. Original statement was 'This store is dirty'.

$\S Q u e s t i o n$ was reverse coded. Original statement was 'This store is dangerous'.

"Q Question was reverse coded. Original statement was 'The food sold at this store is expensive'.

Table 3 Perceptions of corner stores, store patronage, food purchasing and fruit and vegetable consumption by time and intervention status among the Proyecto MercadoFRESCO patron sample ( $n$ 957), East Los Angeles and Boyle Heights, California, USA, mid-2011 to 2015

\begin{tabular}{|c|c|c|c|c|c|c|c|c|c|c|}
\hline & \multicolumn{4}{|c|}{ Intervention } & \multicolumn{4}{|c|}{ Comparison } & \multirow{2}{*}{\multicolumn{2}{|c|}{$\begin{array}{l}\text { Mean or percentage } \\
\text { difference } \\
\text { (follow-up - baseline) }\end{array}$}} \\
\hline & \multicolumn{2}{|c|}{$\begin{array}{l}\text { Baseline } \\
(n \text { 264) }\end{array}$} & \multicolumn{2}{|c|}{$\begin{array}{l}\text { Follow-up } \\
(n \text { 208) }\end{array}$} & \multicolumn{2}{|c|}{$\begin{array}{l}\text { Baseline } \\
(n 286)\end{array}$} & \multicolumn{2}{|c|}{$\begin{array}{l}\text { Follow-up } \\
(n \text { 199) }\end{array}$} & & \\
\hline & $\begin{array}{l}\text { Mean } \\
\text { or } \%\end{array}$ & SD & $\begin{array}{l}\text { Mean } \\
\text { or \% }\end{array}$ & SD & $\begin{array}{l}\text { Mean } \\
\text { or \% }\end{array}$ & SD & $\begin{array}{l}\text { Mean } \\
\text { or \% }\end{array}$ & SD & Intervention & Comparison \\
\hline $\begin{array}{l}\text { Overall perceptions about corner stores score } \\
\text { (range: } 0-15 \text { ) }\end{array}$ & $10 \cdot 8$ & $3 \cdot 1$ & $13 \cdot 1^{* \star *}$ & $2 \cdot 1$ & $10 \cdot 3$ & $3 \cdot 2$ & $11 \cdot 1^{\star \star}$ & $2 \cdot 7$ & $2 \cdot 3$ & $0.9^{\star \star \star}$ \\
\hline $\begin{array}{l}\text { Shops at corner store at least a few times per } \\
\text { week } \dagger\end{array}$ & $83 \cdot 7$ & - & $88 \cdot 5$ & - & $86 \cdot 4$ & - & $94 \cdot 5^{\star \star}$ & - & 4.7 & $8 \cdot 1$ \\
\hline Dollars spent on food per week & $120 \cdot 5$ & $74 \cdot 3$ & $122 \cdot 7$ & $72 \cdot 5$ & $132 \cdot 4$ & $80 \cdot 0$ & 128.9 & 73.5 & $2 \cdot 2$ & $-3 \cdot 6$ \\
\hline Dollars spent on fruits and vegetables per week & $40 \cdot 0$ & 30.7 & $40 \cdot 8$ & 27.5 & 45.4 & $36 \cdot 3$ & $46 \cdot 1$ & $37 \cdot 8$ & 0.9 & 0.7 \\
\hline $\begin{array}{l}\text { Percentage of dollars spent on fruits and } \\
\text { vegetables }\end{array}$ & $34 \cdot 1$ & $15 \cdot 7$ & $35 \cdot 7$ & $16 \cdot 5$ & $35 \cdot 3$ & $16 \cdot 6$ & $36 \cdot 8$ & $25 \cdot 1$ & $1 \cdot 7$ & 1.5 \\
\hline $\begin{array}{l}\text { Number of fruits and vegetables purchased at } \\
\text { corner store at this visit }\end{array}$ & 0.2 & 0.6 & $0.5^{\star \star \star}$ & $1 \cdot 1$ & 0.5 & $1 \cdot 2$ & 0.4 & 0.9 & 0.3 & $0.0^{\star \star \star}$ \\
\hline $\begin{array}{l}\text { Servings of fruits and vegetables consumed each } \\
\text { day }\end{array}$ & $4 \cdot 8$ & 3.0 & 4.9 & $2 \cdot 7$ & $5 \cdot 2$ & 3.1 & 4.9 & $2 \cdot 8$ & 0.1 & -0.3 \\
\hline
\end{tabular}

Significant differences in continuous variables were tested between intervention baseline and follow-up using independent-sample $t$ tests, comparison baseline and follow-up using independent-sample $t$ tests tests, and mean difference (follow-up - baseline) for intervention and comparison using an $F$ test on the interaction term of a linear regression. Significant differences in binary variables were tested between intervention baseline and follow-up using $X^{2}$ tests, comparison baseline and followup using $x^{2}$ tests, and percentage difference (follow-up - baseline) for intervention and comparison using a Wald test on the interaction term of a logistic regression. This Wald test can be thought of as testing whether the relative change (on an odds ratio scale) is the same in the intervention and comparison groups. Percentage difference may vary slightly from reported percentage follow-up - reported percentage baseline due to rounding.

${ }^{\star \star} P<0.01,{ }^{\star \star \star} P<0.001$.

†Binary variable; 0 combines 'a few times a month' and 'every once in a while'; 1 combines 'a few times a week', 'more than once per day' and 'once per day'.

follow-up for both intervention arms. Participants reported consuming on average approximately 5 servings of F\&V daily. No substantial intervention effect was found for consumption when testing for an interaction between time and intervention status (see Table 3). 


\section{Exposure time}

In order to test for an effect due to the staggered timeline associated with corner store conversions, we incorporated a time of exposure to the converted corner store variable (i.e. number of days between the corner store reopening to follow-up data collection) into our regression models (data not shown). The time of exposure interaction was significantly associated with only one of the fifteen individual items testing corner store perceptions. However, the coefficient associated with predicting 'This store sells a wide variety of fresh fruits' was very small and did not change the conclusion of the results. Additionally, the regression coefficients for the interactions were not significant in any of the regression models predicting overall perceptions of the corner stores, store patronage, food purchasing or F\&V consumption.

\section{Discussion}

Public and private entities have made substantial investments over the past few years in corner store conversions and other efforts to improve both food deserts and food swamps. In 2011 alone, the US federal government allocated \$US 400 million to increase access to supermarkets and other healthy food options in food deserts ${ }^{(26)}$ ('food deserts' being the term more commonly used than 'food swamps'). The California FreshWorks Fund Initiative is a \$US 260 million loan fund that seeks to bring grocery stores, 'healthy' corner stores and other healthy food retailers to food deserts ${ }^{(37)}$. In Philadelphia, the Food Trust and the Philadelphia Department of Public Health teamed up to develop the Healthy Corner Store Initiative, a network of over 600 corner stores committed to selling healthy products ${ }^{(38)}$. Despite the large financial and time investments of these environmental change interventions, there is little experimental or quasi-experimental evidence suggesting that this approach will yield substantial improvements in the healthfulness of diets or substantial reductions in obesity ${ }^{(17)}$. Given the considerable resources dedicated to improving healthy food access, it is imperative to comprehensively assess both the impacts and costs of corner store conversions to understand the extent to which they should be considered an integral component of obesity reduction strategies going forward.

In the present study, we examined the effects on store patrons of a corner store conversion intervention in the predominantly Mexican-American neighbourhoods of East Los Angeles and Boyle Heights, California, USA. Relative to patrons of comparison stores, those who shopped at intervention stores demonstrated more favourable perceptions of corner stores and increased purchasing of F\&V during that store visit, but we were not able to detect significant changes in overall purchasing or consumption of F\&V. Our findings related to improved perceptions are squarely in line with other research regarding the psychosocial impacts of corner stores post-intervention ${ }^{(39-43)}$.
As previously discussed, intervention studies have been somewhat equivocal with regard to the impact of corner store conversions on improving food purchasing and dietary practices ${ }^{(21,22,39-43)}$. Although the statistically significant gain we detected in purchasing of $\mathrm{F} \& \mathrm{~V}$ (from $0 \cdot 2$ to 0.5 items per visit) was noteworthy, the magnitude of the difference was still modest, a disappointing finding given that the intervention stores stocked very few or no $\mathrm{F} \& \mathrm{~V}$ prior to the intervention. One potential explanation is that the modest amount of F\&V purchased in the stores may have displaced rather than supplemented produce purchased from other vendors. Although there was a sound basis for anticipating that intervention effects would be greater among store patrons than among neighbourhood residents independent of patronage, and although there was indeed stronger evidence of effects on food purchasing among store patrons than among neighbourhood residents, our present findings do not reverse the impression from our previous research using community surveys $^{(25)}$. Namely, we were not able to find a significant difference in overall consumption of $\mathrm{F} \& \mathrm{~V}$, suggesting that the intervention had little or no effect. However, findings must be interpreted in light of our study limitations.

In general, the findings from Proyecto MercadoFRESCO are consistent with the broader research literature regarding the impact of the food environment on improving disparities in chronic diseases, including type 2 diabetes, CVD and obesity. For well over a decade, researchers have combined data from health surveys with geographic information systems in efforts to understand whether spatial patterns in chronic diseases may reflect inequities in the food and physical activity environments. Many studies based on cross-sectional data have observed an association between features of the food environment and outcomes related to food purchasing, diet, obesity and other related outcomes (see e.g. Moore et al. ${ }^{(44)}$ ). Yet other studies have found little evidence to suggest that there is an association between key environmental factors such as distance from one's home to food outlets and dietary behaviours or weight status ${ }^{(45,46)}$. Cross-sectional research, however, cannot overcome the fundamental selection problem in neighbourhood research, which is that both households and food stores self-select into their neighbourhoods. For example, it is unclear whether residents in food swamps or food deserts eat fewer healthy foods because of lack of healthy food availability, whether stores in food swamps/deserts choose not to sell healthy foods because of lack of demand, or whether unhealthy eating and lack of healthy food options are both the consequence of a shared attribute (e.g. residents in food swamps/deserts lack the income to purchase healthy foods and healthy food vendors only select into neighbourhoods with high average household income). The much more limited longitudinal research on this topic has found more modest relationships between the food environment and health-related outcomes. A notable 
example is Boone-Heinonen et al. in 2011, who used 15-year data from the Coronary Artery Risk Development in Young Adults study and found that supermarket availability was largely unrelated to diet quality and that the effects of access to smaller grocery or corner stores was equivocal. Increased access to fast-food establishments was associated with increased fast-food consumption but only among low-income men ${ }^{(47)}$. When considered in light of the larger food environment literature, which is still undetermined about the impact of the food environment on diet, the mixed findings of the present study and the overall corner store conversion literature may be less surprising.

Our study has limitations that should be acknowledged. First, because it relied on cross-sectional data, causality cannot be inferred. Second, we lacked the resources to include a $24 \mathrm{~h}$ dietary recall or food diary in the patron survey. Although it is common to assess F\&V consumption using questions similar to the ones used herein, these types of questions are cognitively more taxing by requiring respondents to estimate typical consumption. Consequently, data that rely on these types of measures are systematically biased $^{(13)}$. Thus, our findings regarding the impact of the intervention on F\&V consumption might be biased towards the null. The study may have been improved by including a larger number of items that measure consumption of $\mathrm{F} \& \mathrm{~V}$ as these foods are eaten alone and in combination with other items, making it more difficult to estimate the intake of this broad product category with only two questions ${ }^{(13)}$. Third, our findings regarding F\&V purchasing may similarly be biased if participants had a difficult time estimating the amount of money they spent on food per week and on F\&V specifically. In contrast, because we also collected data on purchases immediately after patrons had selected and paid for their items, the food purchasing measure related to their current store visits can be expected to be fairly accurate. However, we did not assess the veracity of selfreported $\mathrm{F} \& \mathrm{~V}$ purchases by reviewing receipts or looking in customer bags. Using an objective measure of purchasing such as store sales data may have strengthened our study. Unfortunately, the study stores were not able to reliably provide these data. Future efforts might consider providing stores with uniform cash registers that are able to accurately record this type of information. Another limitation of the Proyecto MercadoFRESCO study, and many other corner store conversion interventions, is that making healthy changes in one or only a few small corner stores may not be enough to 'move the dial' in terms of the overall healthfulness of the food retail environment in food swamps/deserts. If this is the case, larger-scale studies that make smaller changes at a larger number of vendors (e.g. the Healthy Corner Store Initiative in Philadelphia) may prove more successful at improving dietary practices and related outcomes. Finally, it is also important to note that we cannot rule out contamination empirically; however, we believe it is unlikely because both the intervention and comparison areas are densely populated with corner stores.

In light of the evidence emerging from our work, we believe it is important to recognize that changing the dietary behaviours of communities will likely require more time and may require larger-scale environmental change interventions. Research is nascent, and at this time we do not know unequivocally what intervention, message or policy solution will lead to improved dietary behaviours and improved population health. We believe strategies should be more comprehensive and include multiple types of retail food outlets such as existing grocery stores, corner stores, restaurants, food trucks and push carts as a way of improving communities that are inundated with unhealthy options. We also believe it is necessary to shift the spotlight away from promoting consumption of healthier foods to decreasing consumption of unhealthy discretionary energy that comes from things like cookies, candy, salty snacks and sugarsweetened beverages ${ }^{(48)}$. Secular trends in dietary practices and obesity, particularly in low-income communities, can be expected to reflect concurrent changes in both the food environment and the availability and marketing of unhealthy energy-dense foods. Therefore, we also support efforts to implement more wide-sweeping policy levers that could be used to limit the availability, affordability and marketing of unhealthy foods.

\section{Acknowledgements}

Acknowledgements: The authors thank Scott Friedlander for his help with the data analyses. Financial support: This study was funded by two grants from the National Heart, Lung, and Blood Institute (NHLBI) of the National Institutes of Health (NIH) (grant numbers P50 HL105188 and R25 HL108854). NHLBI had no role in the design, analysis or writing of this article. Conflict of interest: None. Authorship: S.L.A. conceived of the study and led the data analyses, interpretation of data and drafting of the manuscript. B.A.L. and M.Z.S. contributed to the interpretation of study results and drafting of the manuscript. A.M.C.-G. carried out the analyses and contributed to the interpretation of study results and drafting of the manuscript. R.E.G. led the acquisition of data efforts and edited the manuscript. M.L.P., D.C.G., T.R.B. and R.B. contributed to the study design, interpretation of data and edited the manuscript. All authors read and approved the final manuscript. A.N.O. oversaw the study's design, implementation, analyses and manuscript development. Ethics of buman subject participation: This study was conducted according to the guidelines laid down in the Declaration of Helsinki and all procedures involving human subjects were approved by the Institutional Review Board of the UCLA Office of the Human Research Protection Program. Written informed consent was obtained from all subjects. 


\section{References}

1. Lisabeth LD, Sanchez BN, Escobar J et al. (2010) The food environment in an urban Mexican American community. Health Place 16, 598-605.

2. Powell LA, Chaloupka FJ \& Bao YJ (2007) The availability of fast-food and full-service restaurants in the United States associations with neighborhood characteristics. Am J Prev Med 33, 4 Suppl., S240-S245.

3. Kwate NOA, Yau C-Y, Loh J-M et al. (2009) Inequality in obesigenic environments: fast food density in New York City. Health Place 15, 364-373.

4. Beaulac J, Kristjansson E \& Cummins S (2009) A systematic review of food deserts, 1966-2007. Prev Chronic Dis 6, A105.

5. Black JL \& Macinko J (2008) Neighborhoods and obesity. Nutr Rev 66, 2-20.

6. Larson NI, Story MT \& Nelson MC (2009) Neighborhood environments: disparities in access to healthy foods in the US. Am J Prev Med 36, 74-81.

7. Walker RE, Keane CR \& Burke JG (2010) Disparities and access to healthy food in the United States: a review of food deserts literature. Health Place 16, 876-884.

8. Black C, Moon G \& Baird J (2014) Dietary inequalities: what is the evidence for the effect of the neighbourhood food environment? Health Place 27, 229-242.

9. Flegal K, Carroll M, Kit B et al. (2012) Prevalence of obesity and trends in the distribution of body mass index among US adults, 1999-2010. JAMA 307, 491-497.

10. Go AS, Mozaffarian D, Roger VL et al. (2014) Heart disease and stroke statistics - 2014 update: a report from the American Heart Association. Circulation 129, e28-e292.

11. Rosenstock S, Whitman S, West JF et al. (2014) Racial disparities in diabetes mortality in the 50 most populous US cities. J Urban Health 91, 873-885.

12. Gaskin DJ, Thorpe RJ, McGinty EE et al. (2014) Disparities in diabetes: the nexus of race, poverty, and place. $A m J$ Public Health 104, 2147-2155.

13. Kirkpatrick SI, Reedy J, Butler EN et al. (2014) Dietary assessment in food environment research a systematic review. Am J Prev Med 46, 94-102.

14. Bodor JN, Ulmer VM, Dunaway LF et al. (2010) The rationale behind small food store interventions in low-income urban neighborhoods: insights from New Orleans. J Nutr 140, 1185-1188.

15. Rose D, Bodor JN, Swalm C et al. (2009) Deserts in New Orleans? Illustrations of Urban Food Access and Implications for Policy. Ann Arbor, MI: University of Michigan National Poverty Center/USDA Economic Research Service Research.

16. Bolen E \& Hecht K (2003) Neighborbood Groceries: New Access to Healthy Food in Low-Income Communities. San Francisco, CA: California Food Policy Advocates.

17. Langellier BA, Garza JR, Prelip ML et al. (2013) Corner store inventories, purchases, and strategies for intervention: a review of the literature. Calif J Health Promot 11, 1-13.

18. Flournoy R (2010) Healthy Food, Healthy Communities: Promising Strategies to Improve Access to Fresh, Healthy Food and Transform Communities. Oakland, CA: PolicyLink.

19. Gittelsohn J, Rowan $M \&$ Gadhoke P (2012) Interventions in small food stores to change the food environment, improve diet, and reduce risk of chronic disease. Prev Chronic Dis 9, E59.

20. Pinard CA, Byker Shanks C, Harden SM et al. (2016) An integrative literature review of small food store research across urban and rural communities in the US. Prev Med Rep 3, 324-332.

21. Ayala GX, Baquero B, Laraia BA et al. (2013) Efficacy of a store-based environmental change intervention compared with a delayed treatment control condition on store customers' intake of fruits and vegetables. Public Health Nutr 16, 1953-1960.
22. Lawman HG, Veur SV, Mallya G et al. (2015) Changes in quantity, spending, and nutritional characteristics of adult, adolescent and child urban corner store purchases after an environmental intervention. Prev Med $\mathbf{7 4}$, $81-85$.

23. Thorndike AN, Bright OM, Dimond MA et al. (2017) Choice architecture to promote fruit and vegetable purchases by families participating in the Special Supplemental Program for Women, Infants, and Children (WIC): randomized corner store pilot study. Public Health Nutr 20, $1297-1305$.

24. Ortega AN, Albert SL, Sharif MZ et al. (2015) Proyecto MercadoFRESCO: a multi-level, community-engaged corner store intervention in East Los Angeles and Boyle Heights. J Commun Health 40, 347-356.

25. Ortega AN, Albert SL, Chan-Golston AM et al. (2016) Substantial improvements not seen in health behaviors following corner store conversions in two Latino food swamps. BMC Public Health 16, 389.

26. Holzman DC (2010) White House proposes healthy food financing initiative. Environ Health Perspect 118, A156.

27. US Census Bureau (2011) The Hispanic Population: 2010. http://www.census.gov/prod/cen2010/briefs/c2010br-04. pdf (accessed July 2015).

28. Modarres A (2013) Boyle Heights: A Brief Demographic and Health Profile. Los Angeles, CA: Pat Brown Institute of Public Affairs, California State University.

29. UCLA Center for Health Policy Research (2013) 2012-2013 Health Profiles. SPA 7: East Los Angeles. http://healthpolicy. ucla.edu/health-profiles/adults/Documents/2012-2013/SPA/ East.pdf (accessed April 2016).

30. UCLA Center for Health Policy Research (2011) Building Healthy Communities: Boyle Heights Health Profile. http://healthpolicy.ucla.edu/chis/bhc/Documents/BHC_Fact_ Sheet_Boyle_Heights.pdf (accessed April 2016).

31. Kipke MD, Iverson E, Moore D et al. (2007) Food and park environments: neighborhood-level risks for childhood obesity in east Los Angeles. J Adolesc Health $\mathbf{4 0}$, 325-333.

32. UCLA Center for Health Policy Research (2013) Many of California's Building Healthy Communities Residents Face Barriers to Healthy Eating. http://healthpolicy.ucla.edu/ publications/Documents/PDF/bhchealthyeatingfs-dec2013. pdf (accessed January 2016).

33. McGuirt JT, Pitts SBJ, Ammerman A et al. (2015) A mixed methods comparison of urban and rural retail corner stores. AIMS Public Health 2, 554-582.

34. Stokols D (1996) Translating social ecological theory into guidelines for community health promotion. Am J Health Promot 10, 282-298.

35. Sharif MZ, Garza JR, Langellier BA et al. (2015) Mobilizing young people in community efforts to improve the food environment: corner store conversions in East Los Angeles. Public Health Rep 130, 406-415.

36. Townsend MS, Kaiser LL, Allen LH et al. (2003) Selecting items for a food behavior checklist for a limited-resource audience. J Nutr Educ Behav 35, 69-82.

37. Yoshida S (2014) Investing in community health: California Freshworks Fund Initiative. Presented at 142nd American Public Health Association Annual Meeting and Exposition, New Orleans, LA, USA, 15-19 November 2014.

38. Sandoval B, Karpyn A \& Aquilante J (2012) Philadelphia's Healthy Corner Store Initiative. Philadelphia, PA: The Food Trust.

39. Gittelsohn J, Anliker J, Sharma S et al. (2008) Impact of food store-based intervention program on psychosocial factors, food purchasing, preparation, and consumption in two american indian communities: results of the Apache Healthy Stores Study. Obesity (Silver Spring) 16, S58-S58. 
40. Gittelsohn J, Dyckman W, Frick KD et al. (2007) A pilot food store intervention in the Republic of the Marshall Islands. Pac Health Dialog 14, 43-53.

41. Gittelsohn J, Vijayadeva V, Davison N et al. (2010) A food store intervention trial improves caregiver psychosocial factors and children's dietary intake in Hawaii. Obesity (Silver Spring) 18, Suppl. 1, S84-S90.

42. Gittelsohn J, Song HJ, Suratkar S et al. (2010) An urban food store intervention positively affects food-related psychosocial variables and food behaviors. Health Educ Behav 37, 390-402.

43. Ho LS, Gittelsohn J, Rimal R et al. (2008) An integrated multi-institutional diabetes prevention program improves knowledge and healthy food acquisition in northwestern Ontario First Nations. Health Educ Behav 35, 561-573.

44. Moore LV, Diez Roux AV, Nettleton JA et al. (2008) Associations of the local food environment with diet quality
- a comparison of assessments based on surveys and geographic information systems: the multi-ethnic study of atherosclerosis. Am J Epidemiol 167, 917-924.

45. Mejia N, Lightstone AS, Basurto-Davila R et al. (2015) Neighborhood food environment, diet, and obesity among Los Angeles County adults, 2011. Prev Chronic Dis 12, E143.

46. Hattori A (2013) Neighborhood food outlets, diet, and obesity among California adults, 2007 and 2009. Prev Chronic Dis 10, E35.

47. Boone-Heinonen J, Gordon-Larsen P, Kiefe CI et al. (2011) Fast food restaurants and food stores longitudinal associations with diet in young to middle-aged adults: the CARDIA Study. Arch Intern Med 171, 1162-1170.

48. Cohen DA, Sturm R, Scott M et al. (2010) Not enough fruit and vegetables too many cookies, candies, salty and soft drinks? Public Health Rep 125, 88-95. 